\title{
Changes in mean platelet volume in critically ill children and its relation to other clinical and laboratory findings.
}

\author{
Abeer Abd Elmoneim ${ }^{1,2 *}$, Abdel Rahman Alhojaili ${ }^{3}$, Noha Reda Banjer ${ }^{3}$, Mohammed Zolaly ${ }^{1}$, Ehab \\ Saoud Abd El-Moneim ${ }^{1,2}$ \\ ${ }^{1}$ Pediatric Department, Taibah University, Almadinah Almounourah, Saudi Arabia \\ ${ }^{2}$ Pediatric Department, Sohag University, Sohag, Egypt \\ ${ }^{3}$ Pediatric Intensive Care Unit (PICU), Maternity and Child Health (MCH) Hospital Almadinah Almounourah, Saudi \\ Arabia
}

\begin{abstract}
Background: Mean Platelet Volume (MPV) is a measure of platelet size, and is influenced by inflammation which is commonly overlooked by clinicians. In critically ill patients, sepsis is a major problem and considered a generalized process that involves all body organs and systems. Hemostatic system is commonly involved in any sepsis condition. The aim of this study is to detect changes of MPV on admission in critically ill children and determine its relation to other clinical and laboratory parameters that can be indicators of sepsis.

Materials and methods: Critically ill children, aged between 1 month and $12 \mathrm{y}$, consecutively presented to Pediatric Intensive Care Unit (PICU) were assessed for possible enrolment in the study. Venous blood samples were collected from all included children at initial presentation, at $12 \mathrm{~h}$ and $48 \mathrm{~h}$ after PICU admission. MPV and other blood indices were measured and compared with systemic inflammatory process serum markers.

Results: Changes in platelets count did not show any significant differences during the first $\mathbf{4 8} \mathbf{~ h}$ in both MPV-rise ( $p=0.22)$ and MPV-no/rise groups $(p=0.09)$. Changes in Procalcitonin (PCT) were significant in MPV-rise ( $p<0.001)$ but not in MPV-no/rise groups $(p=0.06)$.

Conclusions: The results of this study demonstrate a strong relation between the increase in MPV from baseline in critically ill children admitted to PICU with important laboratory and clinical variables.
\end{abstract}

Keywords: Platelet volume, Critically ill children, Sepsis.

Accepted on January 17, 2018

\section{Introduction}

Mean Platelet Volume (MPV) is a simple measure of platelet size that can detect abnormal function and activity of platelets [1]. Increased MPV means more platelet activity and excessive secretion of mediators [2]. It gives an indication about the extent of inflammatory process and activity of disorders like preeclampsia, angina and myocardial infarction and systemic inflammatory conditions, such as ulcerative colitis $[3,4]$. Critically ill patients usually have changes in platelet function and counts that have been studied in previous studies [5-8], where a serious pathophysiologic reaction manifested by decrease in platelet number and function results from the interaction between platelets with pathogen and endothelial cells $[6,7,9,10]$. Increased MPV in the first $72 \mathrm{~h}$ of hospital admission with a marked rise in MPV in non-survivors than in survivors is found in septic inflammatory conditions in adults. Besides, the change in MPV after $72 \mathrm{~h}$ is found to be an independent risk factor of mortality [11].
In critical care settings, patients with systemic infection that associated with organ dysfunction or shock are usually can't be distinguish from those with similar clinical signs but without infection. Traditional inflammatory markers (leukocytes, Creactive protein) can be influenced by parameters other than infection and are slowly released. Contamination usually affects positive bacterial cultural results and negative results do not mean to roll out sepsis [12]. Other laboratory tests are required to give an early indication of infection in inflammatory cases. These tests will replace traditional inflammatory markers that do not have the needed sensitivity and specificity. Procalcitonin (PCT) serum level is one of these needed tests to mark the inflammatory response to infection [5,6,13-15]. Normally, all PCT is transformed to calcitonin inside the thyroid gland after its production. Therefore PCT level in the serum is undetectable $(<0.1 \mathrm{ng} / \mathrm{ml})$ in healthy humans. During severe infections serum PCT levels may increase to over $100 \mathrm{ng} / \mathrm{ml}$. The pathophysiological role of serum PCT during sepsis is not clear [7,14]. During sever 
bacterial, parasitic and fungal infections the level of serum PCT levels increases while in severe viral infections or noninfectious inflammatory reactions, its level does not increase or only shows a moderate increase. The half-life of serum PCT in blood is $25-30 \mathrm{~h}$ while other inflammatory cytokines such as Tumor Necrosis Factor (TNF)- $\alpha$ and Interleukin (IL)- 6 have relatively short half-lives [8]. Serum PCT offers a high level of accuracy in sepsis diagnosis in Intensive Care Unit (ICU) admissions that other currently available tests cannot provide [11]. Depending on these properties, serum PCT can be used as an indicator of severe generalized infections or sepsis. Although MPV in healthy population showed an inverse relationship with platelet count [4], its relation with platelet count and acute phase reactant in infection, specifically critically ill patients, is not well established. The aim of this study is to investigate changes in MPV in critically ill PICU admissions and to determine relation between MPV changes and other clinical and laboratory variables, specifically platelet count and serum PCT level.

\section{Patients and Methods}

\section{Study setting and design}

The study was conducted as a prospective, observational cohort analysis. Data were collected over a period of 5 months (between May 2015 to September 2015) in the PICU of a tertiary care centre, Maternity and Child Health Hospital $(\mathrm{MCH})$, in Almadinah Almounorah, Saudi Arabia. The protocol of the study was approved by the $\mathrm{MCH}$ Hospital research ethics and review board (No: 418). A written informed consent was taken from the legal guardian of each child included in the study. This study was carried out according to the Helsinki Declaration principles [16].

\section{Study population}

Critically ill children, aged between 1 month and $12 \mathrm{y}$, consecutively presented to PICU were assessed for possible enrolment in the study. In the study period a total of 153 PICU admissions were initially considered for the study. Of these, 56 were excluded due to admission diagnoses that might affect the reliability of platelets indices measurements; such as preexisting hematological disorders (immune thrombocytopenic purpura, hereditary macrothrombocytosis, bone marrow aplasia, reactive thrombocytosis, hypersplenism), uremia, laboratory evidence of intravascular disseminated coagulation, uncontrolled hemorrhage, antiplatelets medications, and previous or current anticancer chemotherapy. The final analysis included 45 children, excluding further 52 children who died, discharged or referred to another institution before completing $48 \mathrm{~h}$ of PICU stay. Figure 1 shows a flow diagram of study population.

\section{Data acquisition processing and definitions}

A standardized data collection form was used to collect patient data prospectively. Baseline characteristics including demographic information, baseline diagnosis, baseline laboratory data, medical history, and any co-morbidities were documented on admission. Interventions including use of central venous line, mechanical ventilation, platelets transfusion and RBCs transfusion were recorded for the whole period of PICU stay. Length of PICU stay to the nearest day and PICU all-cause mortality were recorded. To establish disease severity, Pediatric Risk of Mortality (PRISM) Score [17] was calculated from the following parameters: systolic blood pressure, diastolic blood pressure, heart rate, respiratory rate, $\mathrm{PaO}_{2} / \mathrm{FIO}_{2}, \mathrm{PaCO}_{2}, \mathrm{HCO}_{3}^{-}$, prothrombin time/partial thromboplastin time, total serum bilirubin, blood calcium, blood potassium, blood glucose, pupillary reactions and Glasgow coma scale. It was determined according to the worst values within the first $24 \mathrm{~h}$ of admission.

Venous blood samples were collected from all included children at initial presentation, and at 12 and $48 \mathrm{~h}$ after PICU admission to measure the levels of hemoglobin $(\mathrm{Hb}, \mathrm{g} / \mathrm{dL})$, Total Leucocytes Count (TLC), platelet count, MPV (fL) and serum PCT $(\mathrm{pg} / \mathrm{ml})$ at those points of time. Serum PCT was used as a proxy for diagnosing systemic inflammatory response caused by infection. Serum PCT was shown to offer a high level of accuracy in sepsis diagnosis in ICU admissions that other currently available tests cannot provide [6,7,13-15]. For blood elements count, blood samples were collected from an indwelling catheter in tubes that contained EDTA, maintained at $20^{\circ} \mathrm{C}$ and analysed within $1 \mathrm{~h}$ by a laser machine (SYSMEX SE9500 DASIT). For analysis of serum PCT level, $5 \mathrm{ml}$ of whole blood were collected under complete aseptic conditions from each patient. Blood samples were left for 30 to $60 \mathrm{~min}$ for spontaneous clotting at room temperature and then centrifuged at $3000 \mathrm{rpm}$ for $10 \mathrm{~min}$. Serum samples were separated into another set of tubes and were kept frozen at $-20^{\circ} \mathrm{C}$ for detection of serum PCT. PCT level was measured in previously prepared serum of PICU patients using quantitative sandwich Enzyme Linked Immunosorbent Assay (ELISA) technique. Each sample was measured in triplets and the median of the three measures was taken. For PCT we used Human PCT ElISA kit (My BioSource, USA) with the minimum detectable dose of 1 $\mathrm{pg} / \mathrm{ml}$.

Leucopenia was defined as TLC below $4 \times 10^{6} / \mathrm{mm}^{3}$ and leucocytosis as a TLC above $15 \times 10^{6} / \mathrm{mm}^{3}$. Thrombocytopenia was defined as a platelet count below $150 \times$ $109 / \mathrm{mm}^{3}$. MPV change was calculated by subtracting MPV at admission from that at $48 \mathrm{~h}$ after admission $\left(\triangle \mathrm{MPV}_{48} \mathrm{~h}\right.$-adm). The highest procalcitonin level within the first $48 \mathrm{~h}$ was taken for each patient. The number (\%) of patients with the highest procalcitonin level above $150 \mathrm{pg} / \mathrm{ml}$ and those with the highest procalcitonin levels above $2000 \mathrm{pg} / \mathrm{ml}$ were counted. Respiratory failure was defined as the need for artificial ventilation within the first $48 \mathrm{~h}$. Circulatory failure was defined as the need for inotropes and/or vasopressors for at least one hour within the first $48 \mathrm{~h}$.

\section{Statistical analysis}

Based on the $\triangle \mathrm{MPV}_{48 \mathrm{~h} \text {-adm }}$, study population was grouped into two groups, those who showed an increase in MPV (MPV-rise) 
and those who did not show a rise in MPV (MPV-no/rise). Unless otherwise indicated, continuous variables were expressed as median (interquartile range) and categorical variables as number (percentage). The nonparametric test Mann-Whitney-U test was used to compare continuous variables. Chi-square test, $\chi^{2}$, and Fisher's exact test were used to test the differences in categorical variables. Repeated measures over time for platelets and procalcitonin were analysed using the non-parametric Friedman test. Association between $\triangle \mathrm{MPV}_{48} \mathrm{~h}$-adm and other demographic/biochemical parameters were described using Spearman's rank correlation coefficient. A multivariate logistic regression model was implemented to identify the factors associated with the rise in MPV. Data were analysed using SPSS version 16.0 statistical package.

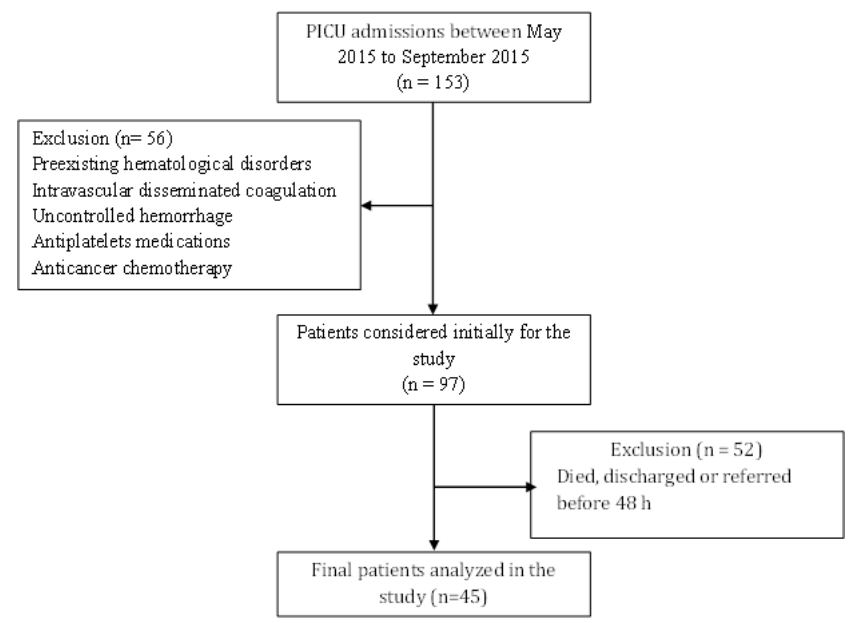

Figure 1. Flow diagram of study population. From May 2015 to September 2015, 153 children who received was admitted to PICU were assessed for possible enrolment according to inclusion and exclusion criteria. Of these 45 children were included in the final analysis.

\section{Results}

The median age (interquartile range) of study participants was 8.0 months (3.5-29.5). Twenty-eight $(62.2 \%)$ were male. PRISM score for study participants was 10.5 (6.0-16.0). For the whole group, MPV on admission was 8.5 (7.5-9.9 fL), whereas $\Delta \mathrm{MPV}_{48 \mathrm{~h} \text {-adm }}$ was $0.10(-0.15-1.00 \mathrm{fL})$. The baseline demographic, clinical, and laboratory characteristics are presented in Table 1 .

Table 1. Demographic, clinical and laboratory baseline data of study cohort $(n=45)$.

\begin{tabular}{|c|c|c|}
\hline Variable & & Total \\
\hline \multirow[t]{3}{*}{ Demographics } & Age (months) & $8.0(3.5-29.5)$ \\
\hline & Male sex, $\mathrm{n}(\%)$ & $28(62.2 \%)$ \\
\hline & PRISM score & $10.5(6.0-16.0)$ \\
\hline
\end{tabular}

$(\%)$

\begin{tabular}{|c|c|c|}
\hline & Circulatory failure, $\mathrm{n}(\%)$ & $7(15.6 \%)$ \\
\hline & Neurological, $n(\%)$ & $7(15.6 \%)$ \\
\hline & Others, $\mathrm{n}(\%)$ & $8(17.8 \%)$ \\
\hline \multirow{7}{*}{$\begin{array}{l}\text { Hematological and } \\
\text { biochemical data at } \\
\text { admission }\end{array}$} & Hemoglobin $(\mathrm{g} / \mathrm{dL})$ & $9.6(8.3-11.5)$ \\
\hline & $\operatorname{TLC}\left(\times 10^{6} / \mathrm{mm}^{3}\right)$ & $11.3(6.5-19.0)$ \\
\hline & Platelets count $\left(\times 10^{9} / \mathrm{mm}^{3}\right)$ & $306(185-410)$ \\
\hline & MPV (fL) & $8.5(7.5-9.9)$ \\
\hline & Procalcitonin (pg/ml) & $186(137-990)$ \\
\hline & Creatinine $(\mathrm{mg} / \mathrm{dL})$ & $0.8(0.6-1.9)$ \\
\hline & Total bilirubin (mg/dL) & $0.6(0.4-1.5)$ \\
\hline \multirow{4}{*}{$\begin{array}{l}\text { Interventions in the first } \\
48 \mathrm{~h}, \mathrm{n}(\%)\end{array}$} & Mechanical ventilation, $\mathrm{n}(\%)$ & $37(82.2 \%)$ \\
\hline & Central venous line, $n(\%)$ & $28(62.2 \%)$ \\
\hline & Platelets transfusion, $\mathrm{n}(\%)$ & $5(11.1 \%)$ \\
\hline & RBCs transfusion, $n(\%)$ & $14(31.1 \%)$ \\
\hline \multirow[t]{2}{*}{ Outcome } & $\operatorname{LOS}(d)$ & $21.0(12.5-31.0)$ \\
\hline & PICU mortality, n (\%) & $8(17.8 \%)$ \\
\hline
\end{tabular}

Although platelets count was higher in the MPV-rise group compared to the MPV-no/rise group, the difference was not statistically significant. Likewise, thrombocytopenia rate in the first $48 \mathrm{~h}$ did not differ between the two groups. Significant difference was evident between the two groups in the highest PCT level recorded in the first $48 \mathrm{~h}$. Figure 2 shows the trend in both platelet count and PCT levels in MPV rise and MPVno/rise groups in the first $48 \mathrm{~h}$ after PICU admission. The changes in platelets count did not show any significant differences during the first $48 \mathrm{~h}$ in both MPV-rise $(\mathrm{p}=0.22)$ and MPV-no/rise groups $(p=0.09)$. On the other hand, the changes in PCT were significant in MPV-rise $(p<0.001)$ but not in MPV-no/rise groups $(\mathrm{p}=0.06)$.
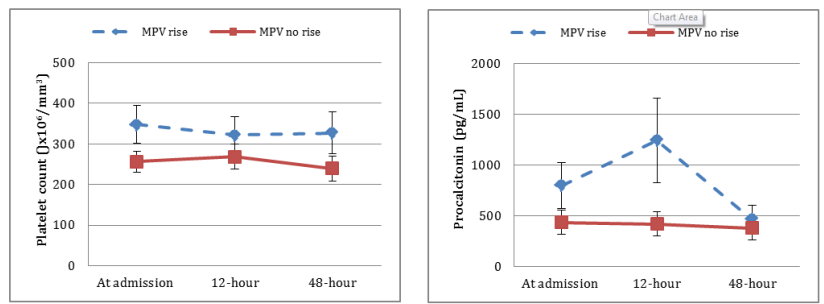

Figure 2. Comparison of trends in the platelet count (A) and procalcitonin levels $(B)$ between MPV rise and MPV-no/rise groups in the first $48 \mathrm{~h}$ after PICU admission. Data are presented as mean and standard error of mean.

Children in the MPV-rise group stayed 30.0 (14.5-46.5 d) in the PICU and had a PICU mortality of $28.6 \%$, while those in the MPV-no/rise group stayed 18.0 (12.3-24.8 d) and had a PICU mortality of $8.3 \%$. The difference between the two groups was statically significant for LOS but not for the PICU mortality. None of the other demographic, clinical, laboratory 
or outcome variables showed a difference between the two groups as shown in Table 2.

Table 2. Comparison of different patients' characteristics according to the rise in MPV.

\begin{tabular}{|c|c|c|c|c|c|}
\hline \multirow[t]{2}{*}{ Variable } & & & \multicolumn{2}{|l|}{ Rise in MPV } & \multirow[t]{2}{*}{ p value } \\
\hline & & & Yes $(n=21)$ & No $(n=24)$ & \\
\hline \multirow[t]{3}{*}{ Demographics } & Age (months) & & $8.0(4.5-15.0)$ & $13.5(3.0-54.8)$ & 0.3 \\
\hline & Male sex, n (\%) & & $15(71.4 \%)$ & $13(54.2 \%)$ & 0.23 \\
\hline & PRISM score & & $10.0(6.5-14.5)$ & $11.0(6.0-16.0)$ & 0.87 \\
\hline \multirow[t]{4}{*}{ Diagnosis category, n (\%) } & Respiratory failure, n (\%) & & $12(57.1 \%)$ & $6(25.0 \%)$ & \\
\hline & Circulatory failure, $\mathrm{n}(\%)$ & & $3(14.3 \%)$ & $4(16.7 \%)$ & \\
\hline & Neurological, n (\%) & & $1(4.8 \%)$ & $6(25.0 \%)$ & \\
\hline & Other, n (\%) & & $2(9.5 \%)$ & $6(25.0 \%)$ & \\
\hline \multirow[t]{14}{*}{ Hematological and biochemical data } & Hemoglobin (g/dL) & & $9.7(8.4-11.3)$ & $9.4(8.3-11.7)$ & 0.74 \\
\hline & TLC at admission $\left(\times 10^{6} / \mathrm{mm}^{3}\right)$ & & $13.9(6.4-20.0)$ & $9.8(6.5-13.9)$ & 0.15 \\
\hline & TLC category, n (\%) & $<4\left(\times 10^{6} / \mathrm{mm}^{3}\right)$ & $2(9.5 \%)$ & $3(12.5 \%)$ & 0.08 \\
\hline & & $4-15\left(\times 10^{6} / \mathrm{mm}^{3}\right)$ & $9(42.9 \%)$ & $17(70.8 \%)$ & \\
\hline & & $>15\left(\times 10^{6} / \mathrm{mm}^{3}\right)$ & $10(47.6 \%)$ & $4(16.7 \%)$ & \\
\hline & $\begin{array}{l}\text { Platelets count at admission ( } \times 10^{9} \text { / } \\
\mathrm{mm}^{3} \text { ) }\end{array}$ & & $398(187-500)$ & $267(152-355)$ & 0.09 \\
\hline & $\begin{array}{l}\text { Thrombocytopenia in the first } 48 \mathrm{~h}, \mathrm{n} \\
(\%)\end{array}$ & & $8(38.1 \%)$ & $9(37.5 \%)$ & 0.96 \\
\hline & $\Delta \mathrm{MPV}_{48 \mathrm{~h}-\mathrm{adm}}$ & & $1.00(0.30-1.95)$ & $-0.10(-1.33-0)$ & $<0.001$ \\
\hline & Procalcitonin at admission $(\mathrm{pg} / \mathrm{ml})$ & & $232(141-1126)$ & $160(103-491)$ & 0.18 \\
\hline & Procalcitonin, highest (pg/ml) & & $451(148-2650)$ & $180(108-696)$ & 0.03 \\
\hline & $\begin{array}{l}\text { Procalcitonin levels above } 150 \mathrm{pg} / \mathrm{ml}, \mathrm{n} \\
(\%)\end{array}$ & & $16(76.2 \%)$ & $16(66.7 \%)$ & 0.48 \\
\hline & $\begin{array}{l}\text { Procalcitonin levels above } 2000 \mathrm{pg} / \mathrm{ml} \text {, } \\
\mathrm{n}(\%)\end{array}$ & & $7(33.3 \%)$ & $2(8.3 \%)$ & 0.03 \\
\hline & Creatinine $(\mathrm{mg} / \mathrm{dL})$ & & $0.9(0.6-2.1)$ & $0.7(0.4-1.2)$ & 0.21 \\
\hline & Total bilirubin (mg/dL) & & $0.5(0.3-1.1)$ & $0.7(0.6-1.7)$ & 0.87 \\
\hline \multirow[t]{4}{*}{ Interventions in the first $48 \mathrm{~h}, \mathrm{n}(\%)$} & Mechanical ventilation, n (\%) & & $16(76.2 \%)$ & $21(87.5 \%)$ & 0.32 \\
\hline & Central venous line, $n(\%)$ & & $14(66.7 \%)$ & $14(58.3 \%)$ & 0.56 \\
\hline & Platelets transfusion, n (\%) & & $4(19.0 \%)$ & $1(4.2 \%)$ & 0.11 \\
\hline & RBCs transfusion, n (\%) & & $8(38.1 \%)$ & $6(25.0 \%)$ & 0.34 \\
\hline \multirow[t]{2}{*}{ Outcome } & $\operatorname{LOS}(d)$ & & $30.0(14.5-46.5)$ & $18.0(12.3-24.8)$ & 0.03 \\
\hline & PICU mortality, n (\%) & & $6(28.6 \%)$ & $2(8.3 \%)$ & 0.12 \\
\hline
\end{tabular}

Table 3 shows the results of the multivariate logistic regression model of factors associated with the $\triangle \mathrm{MPV}_{48} \mathrm{~h}$-adm. Respiratory failure, TLC at admission, the highest PCT level recorded in the first $48 \mathrm{~h}$ and LOS showed a significant positive association with the changes in MPV. These associations remained significant when the model was adjusted for age, sex, and PRISM score. 
Table 3. A multivariate logistic regression model of factors associated with the $\triangle M P V_{48}$ h-adm.

\begin{tabular}{|c|c|c|c|c|}
\hline \multirow[t]{2}{*}{ Variable } & \multicolumn{2}{|l|}{ Unadjusted } & \multicolumn{2}{|l|}{ Adjusted $^{*}$} \\
\hline & $\mathrm{OR}(\mathrm{Cl})^{*}$ & p value & OR $(\mathrm{Cl})^{*}$ & $p$ value \\
\hline Respiratory failure & $26.43(2.25-311.29)$ & 0.009 & $24.79(1.64-375.27)$ & 0.02 \\
\hline TLC at admission & $1.21(1.00-1.46)$ & 0.04 & $1.27(1.00-1.61)$ & 0.04 \\
\hline Platelets count at admission & $1.01(0.99-1.01)$ & 0.2 & $1.01(0.99-1.01)$ & 0.19 \\
\hline Procalcitonin, highest & $1.00(1.00-1.01)$ & 0.01 & $1.00(1.00-1.01)$ & 0.01 \\
\hline LOS & $1.09(1.00-1.20)$ & 0.04 & $1.10(1.00-1.22)$ & 0.04 \\
\hline PICU mortality & $1.50(0.9-26.64)$ & 0.78 & $2.17(0.11-44.36)$ & 0.61 \\
\hline
\end{tabular}

On the other hand, platelets count at admission and PICU mortality did not show significant association with the $\triangle \mathrm{MPV}_{48} \mathrm{~h}$-adm. Spearman's correlation analysis revealed a significant positive correlation between $\triangle \mathrm{MPV}_{48} \mathrm{~h}$-adm and the highest PCT level recorded in the first $48 \mathrm{~h}(\mathrm{rho}=0.32 ; \mathrm{p}=0.03)$, and LOS (rho=0.40; $=0.007$ ) (Table 4).

Table 4. Correlation between $\triangle M P V_{48 \text { h-adm }}$ and variables.

\begin{tabular}{|c|c|c|c|}
\hline \multirow[t]{2}{*}{ Variable } & & \multicolumn{2}{|c|}{$\Delta \mathbf{M P V}_{48 \text { h-adm }}$} \\
\hline & & rho & $p$ value \\
\hline \multirow[t]{2}{*}{ Demographics } & Age (months) & -0.11 & 0.45 \\
\hline & PRISM score & -0.11 & 0.49 \\
\hline \multirow[t]{7}{*}{ Hematological and biochemical data } & Hemoglobin (g/dL) & -0.02 & 0.88 \\
\hline & TLC at admission $\left(\times 10^{6} / \mathrm{mm}^{3}\right)$ & 0.23 & 0.13 \\
\hline & Platelets count at admission $\left(\times 10^{9} / \mathrm{mm}^{3}\right)$ & 0.18 & 0.24 \\
\hline & Procalcitonin at admission $(\mathrm{pg} / \mathrm{ml})$ & 0.21 & 0.15 \\
\hline & Procalcitonin, highest (pg/ml) & 0.32 & 0.03 \\
\hline & Creatinine $(\mathrm{mg} / \mathrm{dL})$ & 0.21 & 0.12 \\
\hline & Total bilirubin (mg/dL) & 0.06 & 0.86 \\
\hline Outcome & $\operatorname{LOS}(d)$ & 0.4 & 0.007 \\
\hline
\end{tabular}

\section{Discussion}

Due to its high mortality rates, critically ill conditions considered a major health problem to physicians. The mortality rates of these conditions depend mainly on the presence of sepsis or organ failure. Therefore, early detection of sepsis, with a simple and easy laboratory test, in this critical group will help in risk stratification, monitoring disease progression and treatment efficacy. Disturbance in platelets is a significant parameter in critically ill patients and the significance of this parameter is higher if they suffer sepsis. Tests that measure changes in platelets count and volume are simple, automated and less costing. In the present study, we hypothesized that the rise seen in MPV in critically ill children during their stay in PICU could be associated to important clinical and laboratory variables as well as patients outcome. Our results demonstrate a strong relation between the increase in MPV during the first 48 hours after PICU admission with infection as an admission diagnosis, respiratory failure, TLC on admission, serum PCT level on admission, PCT highest level, and LOS but has no relation to either platelet count or PICU mortality. Consequently, the present study may indicate that monitoring of MPV can help in risk stratification of critically ill children. Our results are similar to several reports that showed increase in MPV in sepsis. Dastugue et al. reported rise in MPV in patients with shock [18]. Van and Von showed higher MPV values in patients with sepsis than those suffering of localized infection [19]. The same study group suggested that increased MPV in patients diagnosed with bacterial infection may signal the presence of septicemia [19]. Becchi et al. examined the trends of MPV and platelet count during the course of sepsis and found that the average MPV gradually increased in nonsurvivors, whereas it decreased in survivors [20].

The nature of MPV as an inflammatory marker has been suggested by previous studies, which have demonstrated a correlation between a higher MPV and active inflammatory disease [21-23]. Furthermore, advances in the laboratory technology that served accurate quantification of markers showed that MPV reflects both prothrombotic and proinflammatory status [3]. In our study we chose serum PCT, 
which usually increase in the first 24-30 h of sepsis, as a specific laboratory tool for measuring sepsis in order to demonstrate its relation to MPV elevation in critically ill children. The trend in serum PCT changes, in our current study, during the first $48 \mathrm{~h}$ of PICU admission shows significant difference in patients with rise in MPV than those without MPV rise (Figure 2). These results indicate that rise in MPV values during PICU admission can be an indicator of early sepsis. On the other hand, platelet count trend during the first $48 \mathrm{~h}$ of PICU admission shows no significant difference between patients with MPV rise or those without MPV rise (Figure 2). These results demonstrate that MPV behaved independently from platelet count in PICU patients. Generally, patients with sepsis showed thrombocytopenia during the first $4 \mathrm{~d}$ after hospital admission [19], with an inverse relationship between platelet count and MPV [3,4]. Furthermore, in animal models, MPV increased after the induction of sepsis, whereas platelet count changed inversely [24,25]. Alternatively, our results showed that in PICU patients, although the rise in MPV is related to the increase in PCT, which is a strong indicator of sepsis, it has no significant relation to platelet count. This may be explained by the difference in pathophysiology of sepsis between adult and pediatric populations where platelets respond to sepsis through increase in size with no significant changes in count. These results showed that MPV monitoring in PICU patients might be more important than platelet count monitoring to predict early sepsis.

\section{Conclusion}

The results of this study demonstrate a strong relation between the increase in MPV from baseline in critically ill children admitted to PICU with infection, respiratory failure as well as several important laboratory and clinical variables. These findings are evidence that monitoring of MPV my play a role in risk stratification of critically ill children admitted to PICU.

\section{Acknowledgment}

This Manuscript is funded by the Deanship of Scientific Research, at Taibah University (Project 6060), Almadinah Almounourah, Saudi Arabia, and Dr. Abeer Abd Elmoneim is the Main Investigator. The authors greatly thank doctors and nurses staff in PICU at $\mathrm{MCH}$ hospital in Almadinah Almounourah, KSA for their great help in data and sample collection.

\section{References}

1. Arica S, Ozer C, Arica V, Karakus A, Celik T, Gunesacar R. Evaluation of the mean platelet volume in children with familial Mediterranean fever. Rheumatol Int 2012; 32: 3559-3363.

2. Magen E, Mishal J, Zeldin Y, Feldman V, Kidon M, Schlesinger $\mathrm{M}$. Increased mean platelet volume and $\mathrm{C}$ reactive protein levels in patients with chronic urticaria with a positive autologous serum skin test. Am J Med Sci 2010; 339: 504-508.
3. Zdrojewski Z, Raszeja-Specht A, Kustosz J, Skibowska A, Rutkowski B. Evaluation of factors influencing platelet aggregation in patients with chronic glomerulonephritis (CGN). Przegl Lek 1996; 53: 434-438.

4. Karaman H, Karakukcu C, Kocer D. Can mean platelet volume serve as a marker for prostatitis? Int J Med Sci 2013; 10: 1387-1391.

5. Chan YL, Tseng CP, Tsay PK, Chang SS, Chiu TF, Chen JC. Procalcitonin as a marker of bacterial infection in the emergency department: an observational study. Crit Care Med 2004; 8: 12-20.

6. Brunkhorst FM, Wegscheider K, Forycki ZF, Brunkhorst R. Procalcitonin for early diagnosis and differentiation of SIRS, sepsis, severe sepsis, and septic shock. Intensive Care Med 2000; 26: 148-152.

7. Becker KL, Nylen ES, White JC, Müller B, Snider RH. Clinical review 167: Procalcitonin and the calcitonin gene family of peptides in inflammation, infection, and sepsis: a journey from calcitonin back to its precursors. J Clin Endocrinol Metab 2004; 89: 1512-1525.

8. Meisner M. Pathobiochemistry and clinical use of procalcitonin. Clin Chim Acta 2002; 323: 17-29.

9. Thompson CB, Love DG, Quinn PG, Valeri CR. Platelet size does not correlate with platelet age. Blood 1983; 62: 487-494.

10. Bessman JD, Gilmer PR, Gardner HF. Use of mean platelet volume improves detection of platelet disorders. Blood Cells 1985; 11: 127-135.

11. Kim CH, Kim SJ, Lee MJ, Kwon YE, Kim YL, Park KS. An increase in MPV from baseline is associated with mortality in patients with severe sepsis or septic shock. PLoS One 2015; 10: 1-13.

12. Sudhir U, Venkatachalaiah RK, Kumar TA, Rao MY, Kempegowda P. Significance of serum procalcitonin in sepsis. Indian J Crit Care Med 2011; 15: 1-5.

13. Schwarz S, Bertram M, Schwab S, Andrassy K, Hacke W. Serum procalcitonin levels in bacterial and abacterial meningitis. Crit Care Med 2000; 28: 1828-1832.

14. Meisner M. The prognostic value of Procalcitonin. In: Meisner M, editor. Procalcitonin (PCT)-a new, innovative infection parameter. Biochemical and clinical aspects (3rd edn.). New York Thieme Publ 2000; 63-68.

15. Muller B, Becker KL, Schachinger H, Rickenbacher PR, Huber PR, Zimmerli W. Calcitonin precursors are reliable markers of sepsis in a medical intensive care unit. Crit Care Med 2000; 28: 977-983.

16. World Medical Association. Ethical principles for medical research involving human subjects. Eur J Emerg Med 2001; 8: 221-224.

17. Pollack MM, Ruttimann UE, Getson PR. Pediatric risk of mortality (PRISM) score. Crit Care Med 1988; 16: 1110-1116.

18. Dastugue N, Picheloup F, Sie P, Genestal M, Cathala B, Boneu B. Increase in mean platelet volume in shock-related thrombocytopenia. Nouv Presses Med 1982; 11: 2899-2901. 
19. Van der Lelie J, Von dem Borne AK. Increased mean platelet volume in septicaemia. J Clin Pathol 1983; 36: 693-696.

20. Becchi C, Al Malyan M, Fabbri LP, Marsili M, Boddi V, Boncinelli S. Mean platelet volume trend in sepsis: is it a useful parameter? Minerva Anestesiol 2006; 72: 749-756.

21. Jackson SR, Carter JM. Platelet volume: laboratory measurement and clinical application. Blood Rev 1993; 7: 104-113.

22. Bessman JD, Gardner FH. Platelet size in thrombocytopenia due to sepsis. Surg Gynecol Obstet 1983; 156: 177-180.

23. Corash L, Tan H, Gralnick HR. Heterogeneity of human whole blood platelet subpopulations. I. Relationship between buoyant density, cell volume, and ultrastructure. Blood 1977; 49: 71-87.
24. Bath PM, Butterworth RJ. Platelet size: measurement, physiology and vascular disease. Blood Coagul Fibrinolysis 1996; 7: 157-161.

25. Taniguchi T, Takagi D, Takeyama N, Kitazawa Y, Tanaka T. Platelet size and function in septic rats: changes in adenylate pool. J Surg Res 1990; 49: 400-407.

\section{*Correspondence to}

Abeer Abd Elmoneim

Pediatric Department

Taibah University

Saudi Arabia 